\title{
Introduction of Music Therapy Incorporated into Cognitive Remediation: A New Approach to Cognitive Dysfunction in Psychiatric Disorders and a Preliminary Report on Its Effects in Schizophrenia
}

\author{
Naoko Kosugi ${ }^{*}$, Chiaki Oshiyama ${ }^{2}$, Naoki Kodama3 ${ }^{3}$, Shin-Ichi Niwa ${ }^{4}$ \\ ${ }^{1}$ Division of Healthcare Informatics, Faculty of Healthcare, Tokyo Healthcare University, Tokyo, Japan \\ ${ }^{2}$ National Institute of Advanced Industrial Science and Technology (AIST), Artificial Intelligence Research Center, Tokyo, Japan \\ ${ }^{3}$ Department of Radiological Technology, Faculty of Medical Technology, Niigata University of Health and Welfare, Niigata, Japan \\ ${ }^{4}$ Department of Psychiatry, Aizu Medical Center, Fukushima Medical University, Fukushima, Japan \\ Email: ^naonaoan@gmail.com
}

How to cite this paper: Kosugi, N., Oshiyama, C., Kodama, N. and Niwa, S.-I. (2019) Introduction of Music Therapy Incorporated into Cognitive Remediation: A New Approach to Cognitive Dysfunction in Psychiatric Disorders and a Preliminary Report on Its Effects in Schizophrenia. Open Journal of Psychiatry, 9, 23-38. https://doi.org/10.4236/ojpsych.2019.91003

Received: December 3, 2018

Accepted: January 15, 2019

Published: January 18, 2019

Copyright $\odot 2019$ by author (s) and Scientific Research Publishing Inc. This work is licensed under the Creative Commons Attribution International License (CC BY 4.0).

http://creativecommons.org/licenses/by/4.0/

\section{(c) (i) Open Access}

\begin{abstract}
Aim: Cognitive dysfunction and negative symptoms interfere social participation in patients with schizophrenia. Cognitive remediation has proven effective for cognitive deficits. While there are few effective treatments for the negative symptoms of schizophrenia, music therapy is expected to ameliorate negative symptoms. With the goal of improving both cognitive dysfunction and negative symptoms, we originally developed a program of Music Therapy incorporated into Cognitive Remediation (MTCR). We introduce the MTCR program and our preliminary results of conducting MTCR in patients with schizophrenia. Methods: The program was based on the NEAR (neuropsychological educational approach to cognitive remediation) program. The MTCR program uses instrumental performances and ensemble vocal performances to train cognitive functions, which consists of 30 sessions in total, with each session being 60 minutes long ( 45 minutes of music, 15 minutes of verbal session). The participants attended sessions semiweekly in groups of fewer than 12 members. We measured the participants' symptoms twice, before the intervention and after the final session. For both measurements, we used the BACS and BPRS. Thirty-six individuals ( 26 men, 10 women; average age of 42.4 years) with schizophrenia participated in this study. They participated in an average of 28.2 sessions. Results: BACS total scores $(\mathrm{p}<0.05)$, "verbal fluency" $(\mathrm{p}<0.01)$ and "attention" $(\mathrm{p}<0.02)$ subtests improved sig-
\end{abstract}


nificantly. Overall BPRS scores were essentially unchanged, but significant improvement was observed in the "emotional withdrawal" $(\mathrm{p}<0.05)$ and "blunted affect" ( $\mathrm{p}<0.07)$. "Hostility" ( $\mathrm{p}<0.05)$, "bizarre behavior" ( $<$ $0.01)$, "mannerisms and posturing" ( $\mathrm{p}<0.01)$, and "disorientation" $(\mathrm{p}<0.03)$ also improved significantly. Conclusions: The present study demonstrated that MTCR program can improve both cognitive dysfunction and negative symptoms of patients with schizophrenia, which implies that it can also potentially facilitate the social participation of such patients.

\section{Keywords}

Schizophrenia, Cognitive Remediation, Music Therapy, Social Participation, BACS, BPRS

\section{Introduction}

Schizophrenia incurs significant burdens to society [1]. With onset typically occurring during the 20s and 30s, schizophrenia brings significant economic losses [2] [3], and the burden and loss to patients and their family members are immeasurable [4]. Therefore, recovery support is paramount.

Cognitive dysfunction and negative symptoms interfere with social participation, making social participation difficult for patients with schizophrenia [5] [6] [7] [8]. There are a number of therapies available for cognitive deficits, including cognitive remediation (CR), cognitive behavioral therapy (CBT), and occupational therapy (OT), and these therapies have proven effective [9] [10]. On the other hand, there are few effective treatments for the negative symptoms of schizophrenia [11], owing to the difficulties and costs involved [11] [12]. There is, however, evidence that music therapy can ameliorate negative symptoms [13] [14].

It has recently been reported that $\mathrm{CR}$ can also lead to improvements in negative symptoms of schizophrenia. Ventura et al., for example, assessed symptoms using the Scale for the Assessment of Negative Symptoms (SANS) and the Brief Psychiatric Rating Scale (BPRS), and they reported improvements in SANS-assessed affective flattening and alogia, and in BPRS-assessed affective flattening [11]. In a network meta-analysis, Cella et al. reported that CR was associated with an improvement of negative symptoms and that it is effective for reducing the level of post-therapy negative symptoms [15]. There are also reports that music therapy leads to improvements in mental state and social functioning [13] [14]. Geretsegger et al. [14] for example, used the paced auditory serial-addition task (PASAT) and the "Wisconsin card sorting test - correctly completed categories" (WCST-Cc), and they reported improvements in PASAT-assessed attention and in WCST-Cc-assessed abstract thinking. The study assessed social functioning based on Social Disability Screening Schedule (SDSS) scores and found significant effects favoring music therapy [14]. 
With the goal of improving both cognitive dysfunction and negative symptoms, we originally developed a program of Music Therapy incorporated into Cognitive Remediation (MTCR program). We very briefly reported a limited part of MTCR program elsewhere [16]. In the present report, we will introduce the whole program of MTCR in detail. The MTCR program uses instrumental performances and ensemble vocal performances to train cognitive functions such as verbal/reasoning skills and social skills. In the beginning and the ending in every session, we had the participants perform the same song together in order to enhance group cohesion. We also incorporated time during sessions for participants to request songs to sing, so as to help participants enjoy the process of in-group communication. At the end of each session, the participants performed a musical number with the difficulty and completion level steadily rising each time. This feature was intended to encourage participants to continue in the program and to give them a sense of satisfaction for participating in the session. To verify the effectiveness of our MTCR program, we conducted a study on the people who attend daycare services, and we report the results of the study herein. This clinical study was approved by the relevant ethics committee of Takasaki University of Health and Welfare (No. 2829). This study was conducted during the time period of August, 2016, to May, 2017.

\section{Method}

\subsection{Subjects}

Regarding our criteria for inclusion in the study, we only recruited those who

1) had been diagnosed with schizophrenia based on the DSM-IV [17],

2) consented to participate,

3) were attending daycare services or workshops,

4) had been in the facility for at least three months,

5) could attend semiweekly sessions over a four-month period,

6) could engage in group activities,

7) were in the 18 - 60 age range,

8) had attended regular classes during their schooling and graduated from junior high school,

9) had no visual or hearing impairments, and

10) could use one or both hands relatively freely.

As for the exclusion criteria, we excluded those who did not want to engage in music for whatever reason. We obtained the participants' informed consent, having briefed them in writing that we had designed the program with the aim of improving cognitive deficits in persons with schizophrenia and that we were asking them to participate in our study for verifying the MTCR program's effectiveness. As a result, the characteristics of the participants were as follows; 1) the mean age \pm SD, $42.4 \pm 9.0$ years old, 2 ) the mean duration after onset \pm SD, 20.3 \pm 10.6 years, 3 ) the mean years of treatment \pm SD, $17.7 \pm 9.4$ years, and 4 ) the 
mean education years $\pm \mathrm{SD}, 12.4 \pm 4.0$ years.

\subsection{Procedures}

The participants attended the 30 sessions in groups of fewer than 12 members. The sessions were held semiweekly, and the period of intervention amounted to approximately four months in total. Immediately after the end of each session, the participants completed the questionnaire shown in Figure 1. We measured the participants' symptoms twice; the first measurement was before the intervention and the second was after the $30^{\text {th }}$ and final session-approximately four months after the first session. For both measurements, we used two diagnostic tools: The Brief Assessment of Cognition in Schizophrenia (BACS) [18] and BPRS. Regarding BACS, we used two versions of it, one for the first measurement of before intervention and the other for the second measurement of after the final session, in order to avoid the learning effect.

\subsection{Overview of MTCR Program}

The MTCR is a rehabilitation program that ameliorates cognitive dysfunction using music in combination with cognitive remediation. The purpose of the MTCR program is to improve cognitive performance and negative symptoms simultaneously.

The program was based on the NEAR (neuropsychological educational approach to cognitive remediation) program [19] [20]. NEAR consists of cognitive sessions and verbal sessions (the latter of which are also called "bridging groups";

\section{Questionnaire for Today's Session}

Please indicate your response to each question by ticking $(\square)$ the appropriate box.

1. Did you concentrate in today's session?

$\square$ Yes, I concentrated thoroughly.

$\square$ I'm not sure.

$\square$ No, I didn't concentrate at all.

2. Did you find today's session difficult or exhausting?

$\square$ No, it was not difficult or exhausting at all.

$\square$ I'm not sure.

$\square$ Yes, it was very difficult and exhausting.

3. Did you find it easy to understand the content of today's session?

$\square$ Yes, it was easy to understand.

$\square$ It was somewhat easy to understand.

$\square$ No, I couldn't understand it at all.

4. Did you enjoy today's session?

$\square$ Yes, I enjoyed it.

$\square$ No, I did not enjoy it.

$\square$ Neither of the two above answers apply.

Figure 1. Questionnaire requested to complete after the end of each session. 
[20]). In cognitive sessions, clients perform cognitive training using computer games, such as spot-the-difference and word-based puzzles. The verbal session involves a group discussion, the aim of which is to help clients apply their trained cognitive functions in actual life settings such as work and school. Examples of the content discussed include making plans, prioritizing tasks, and social skills.

For the verbal sessions in our MTCR program, we used largely the same activities proposed in NEAR. However, instead of computer games-based cognitive training, we used musical activities (which we refer to as "music sessions"). We designed the content of the music sessions based on the verbal sessions. The MTCR program consists of 30 sessions in total (see Table 1 cited from [16]). Table 1 shows the break-down of the sessions. Each session is 60 minutes long (45 minutes of music session, 15 minutes of verbal session). Table 2 shows how time is allotted in each session.

Table 1. Exact contents of the 30-session program (cited from [16]).

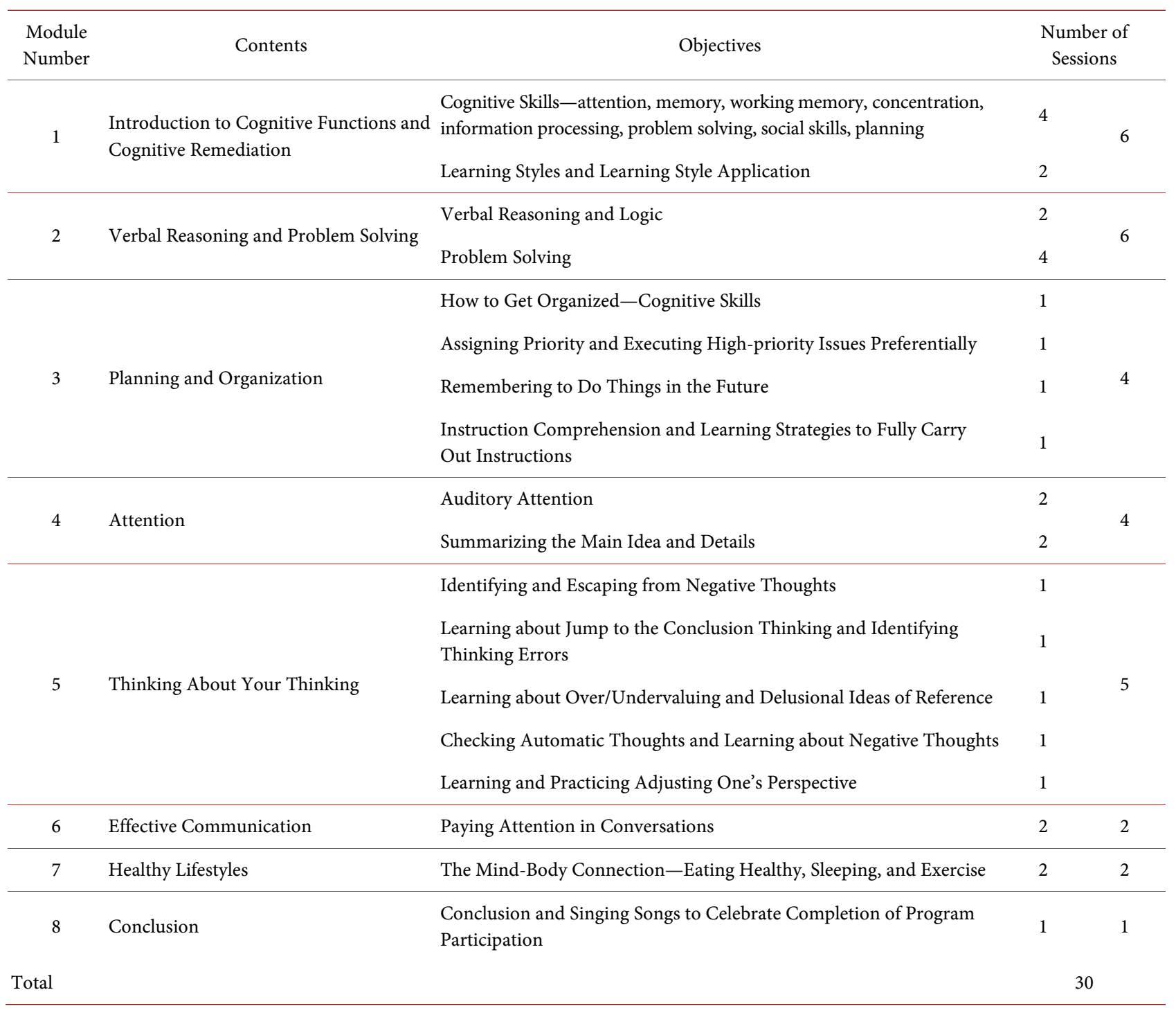


Table 2. Time allotment for each session.

\begin{tabular}{ccc}
\hline Content & Purpose & Time \\
\hline Introduction & Enhance group cohesiveness and processing speed & $5-7 \mathrm{~min}$ \\
Cognitive training 1 & & $15 \mathrm{~min}$ \\
Music by request & Encourage participants to relax and enjoy themselves & $2-3 \mathrm{~min}$ \\
Cognitive training 2 & & $15 \mathrm{~min}$ \\
Ensemble performance & Motivate participants to continue the program & $5-7 \mathrm{~min}$ \\
verbal session & To encourage participants to verbalize & $15 \mathrm{~min}$ \\
& Total & $60 \mathrm{~min}$ \\
\hline
\end{tabular}

\subsubsection{Overview of Music Session}

We made the contents of the music sessions enjoyable through music activities such as singing and playing the instruments. At the start of the session, the participants sing a starting song (an original composition). Singing the same song each time helps make the participants aware that the music session is beginning. The participants then play Shiritori (a word game in which players say a word beginning with the final kana of the previous word) in order to boost their processing speed. For the first session, the standard rules of Shiritori are applied, but more advanced rules are gradually introduced in successive sessions. An example of an advanced rule is that players must clap in rhythm and keep time with the music played by a music therapist. The aim of these advanced rules is to convey the importance of timing and to encourage the participants to time their utterances appropriately. After Shiritori, the participants commence cognitive training (the details of which are outlined in 2.3.2). Cognitive training consists of two tasks, typically taking around 15 minutes to complete. The more difficult tasks take 30 minutes to complete. Between the two cognitive training tasks, the participants sing a song that one of them requested so that they relax and enjoy themselves. After the participants complete the two cognitive training tasks, the session concludes with an ensemble musical performance. The session-end ensemble performances culminate in a grand performance at the end of the $30^{\text {th }}$ session. We hoped that by gradually improving the musical performance with each session, the participants would be more motivated to continue until the final session.

\subsubsection{Music-Based Cognitive Training}

We outline some of the music-based cognitive training tasks. Please see Appendix for detailed descriptions of all 30 of the music sessions. Those readers who wish to know the exact contents of MTCR Program are encouraged to write to Naoko Kosugi (NK) at naonaoan@gmail.com asking NK to send the file of Appendix through e-mail.

In training for social skills, (Module \#1 in Table 1), the research participants played tambourines in pairs. One holds the tambourine while the other holds the stick. The person holding the tambourine holds it out and at an angle that is easy to strike for the person with the stick. Simultaneously, the person striking the 
tambourine with the stick tries to pay attention to the force with which he/she strikes the tambourine so as not to make the other person uncomfortable. In this way, the two participants can learn how to be considerate toward each other.

For training in verbal deduction (Module \#2 in Table 1), we handed participants cards that displayed the lyrics to the relevant song but with some of the lyrics missing. The participants had to infer the missing words or phrases. An important aspect of this task was for participants to 1) think of words or phrases that would fit with the surrounding content and be consistent with the overall theme of the lyrics, and to 2) consider the existing lyrics and ensure that the words or phrases they choose are of such a length that they could be completely vocalized in the time it takes to sing the lyrics.

For training in working memory (Module \#1 in Table 1), the number of times that research participants clap their hands while singing is gradually increased phrase by phrase.

In the training for changing negative thinking (Module \#5 in Table 1), participants learn that they may begin to enjoy activities by becoming aware of their habit of jump to the conclusions, by being shown examples and changing their way of thinking about things. Specifically, the music therapist first hands out the sheet music for In the Mood to the participants, before abruptly saying, "Now, let's clap the rhythm." This action induces a negative mindset among the participants because they assume the music appears too complicated for them to clap along to. Then, the music therapist plays In the Mood on the keyboard. The participants soon notice that it is a cheerful and fun song that they know and become a bit excited. With the music therapist's encouragement and teaching by example, the participants gradually improve their clapping along to the music, which puts them in a good mood. Through this, the participants can avoid having a negative mindset-the tendency in difficult or unfamiliar situations to hastily conclude that they cannot cope with the situation. Instead, they learn that they can enjoy it if they change their way of thinking. In this way, the research participants are enabled to do many kinds of group activities using music as the cognitive remediation.

\subsubsection{Materials}

We outline some of the materials we prepared for the MTCR program.

1) Personal whiteboards (1 per participant): During the music and verbal sessions, the participants used the whiteboards to write down their answers to the music therapist's questions. The purpose of these whiteboards was to minimize discrepancies in degree of participation. In the group sessions, one participant sometimes answers the therapist's question in place of other participants. Such cases lead to a discrepancy in the degree of engagement in the training, with some participants being more responsive to questions, while others are more passive. Such discrepancy may affect the outcomes of the program.

2) Cards

a) Cognitive performance: The cards were for learning about cognitive func- 
tion. The cards displayed words related to cognitive performance (e.g., focus, concentration, transition, allocation, etc.)

b) Action cards: These cards were for learning about plan-making and task-prioritization. The cards displayed written descriptions of tasks (see Figure 2).

3) Musical instruments

a) Wooden clappers (naruko): We prepared enough naruko for a group. We used the naruko when everybody played together the same musical instruments.

b) Percussion instruments: Percussion instruments were used during musical performances. Each participant played a different instrument, including maracas, cabaças, claves, and castanets.

c) Handbells: These were used during melodic performances. Each handbell had a different pitch.

\subsection{Measures}

We used BACS to assess cognitive performance, and BPRS to assess psychiatric symptoms. We also conducted a questionnaire (Figure 1) to measure how far the participants concentrated in the sessions and how easily they could understand the content of the sessions, and whether they were enjoying themselves.

\subsection{Statistical Analysis}

To evaluate the effectiveness of the MTCR program, we assessed the participants with BACS and BPRS before (baseline) and after the 30 sessions and subjected

\begin{tabular}{|l|l|l|l|l|l|l|}
\hline $\begin{array}{l}\text { (1) Do rock-paper- } \\
\text { scissors }\end{array}$ & $\begin{array}{l}\text { (2) Sing a } \\
\text { song }\end{array}$ & $\begin{array}{l}\text { (3) Lay out the } \\
\text { musical } \\
\text { instruments }\end{array}$ & $\begin{array}{l}\text { (4) Decide which } \\
\text { musical instruments } \\
\text { to use }\end{array}$ & \multicolumn{2}{l|}{$\begin{array}{l}\text { (5) Clear away the musical } \\
\text { instruments }\end{array}$} \\
\hline $\begin{array}{l}\text { (6) Use a handbell to } \\
\text { practice your part in } \\
\text { the musical } \\
\text { performance }\end{array}$ & $\begin{array}{l}\text { (7) Sing while clapping the } \\
\text { rhythm }\end{array}$ & $\begin{array}{l}\text { (8) Decide the song in } \\
\text { a group }\end{array}$ & $\begin{array}{l}\text { (9) Collect the lyric sheets } \\
\text { and store them in the box }\end{array}$ \\
\hline $\begin{array}{l}\text { (10) Hand out the lyric } \\
\text { sheets }\end{array}$ & $\begin{array}{l}\text { (11) Decide how } \\
\text { much of the song } \\
\text { to sing or play }\end{array}$ & $\begin{array}{l}\text { (12) Perform } \\
\text { together }\end{array}$ & $\begin{array}{l}\text { (13) Prepare the } \\
\text { lyric sheets for the } \\
\text { performance }\end{array}$ & $\begin{array}{l}\text { (14) Decide who will play } \\
\text { which instruments }\end{array}$ \\
\hline $\begin{array}{l}\text { (15) Decide what you } \\
\text { will do (will it be an } \\
\text { ensemble instrumental } \\
\text { performance or an } \\
\text { ensemble vocal music } \\
\text { performance?) }\end{array}$ & $\begin{array}{l}\text { (16) Ask your } \\
\text { music therapist } \\
\text { to accompany } \\
\text { your } \\
\text { performance }\end{array}$ & $\begin{array}{l}\text { (17) Mark your lyric } \\
\text { sheet to indicate the } \\
\text { moments when you } \\
\text { ring a handbell }\end{array}$ & $\begin{array}{l}\text { (18) Check the } \\
\text { weather and tell } \\
\text { your music } \\
\text { therapist }\end{array}$ & $\begin{array}{l}\text { (19) Decide who take charge } \\
\text { will which pitch of } \\
\text { handbell }\end{array}$ \\
\hline $\begin{array}{l}\text { (20) Conduct the } \\
\text { performance from the } \\
\text { front }\end{array}$ & $\begin{array}{l}\text { (21) Tidy the } \\
\text { contents of the } \\
\text { box }\end{array}$ & $\begin{array}{l}\text { (22) Practice your } \\
\text { singing voice }\end{array}$ & $\begin{array}{l}\text { (23) Decide } \\
\text { who sings first }\end{array}$ & $\begin{array}{l}\text { (24) Decide who sings } \\
\text { later }\end{array}$ \\
\hline $\begin{array}{l}\text { (25) Hold hands with } \\
\text { the person next to you } \\
\text { and go around the } \\
\text { group to make a circle }\end{array}$ & $\begin{array}{l}\text { (26) Decide } \\
\text { where everyone } \\
\text { stands in the line } \\
\text { (up to \#) }\end{array}$ & $\begin{array}{l}\text { (27) Have one person } \\
\text { hold a frame drum, and } \\
\text { another person beat it } \\
\text { with a mallet to create } \\
\text { a rhythm }\end{array}$ & $\begin{array}{l}\text { (28) } \\
\text { Tune } \\
\text { your } \\
\text { voice }\end{array}$ & $\begin{array}{l}\text { (29) Sing the song to } \\
\text { practice the notes that } \\
\text { you will play with your } \\
\text { instrument }\end{array}$ \\
\hline
\end{tabular}

Figure 2. Action cards. 
the results to a t-test.

\section{Results}

\subsection{Research Participant Characteristics}

Thirty-six persons ( 26 men, 10 women; average age of 42.4 years) participated in this study. They participated in an average of 28.2 sessions. The lowest number of sessions attended was 23 and the highest was 30 , and 11 participants attended all 30 sessions. A limited part of the results is reported elsewhere [16]. In the following, we report the whole results in detail.

\subsection{Effectiveness of MTCR Program}

Table 3 shows the results for BACS and Table 4 shows the results for BPRS. In Table 3, the BACS values for baseline and after the 30 sessions are indicated as the differences from the normative values of healthy subjects according to the usual describing way for BACS.

BACS total scores improved significantly $(-2.30 \rightarrow-2.02, \mathrm{t}(35)=-2.11, \mathrm{p}=$ 0.042) after participation in the program; significant improvements were also observed in "verbal fluency" $(-1.22 \rightarrow-0.98, \mathrm{t}(35)=-2.88, \mathrm{p}=0.007)$ and "attention" $(-2.02 \rightarrow-1.77, \mathrm{t}(35)=-2.57, \mathrm{p}=0.015)$ subtests (here, the scores for BACS indicate how much cognitive functions decay from the average of healthy subjects.).

Overall BPRS scores were essentially unchanged $(30.72 \rightarrow 29.47, \mathrm{t}(35)=0.80$, $\mathrm{p}=0.427)$, but significant improvement was observed in the "emotional withdrawal" and "blunted affect" $(3.42 \rightarrow 2.78, \mathrm{t}(35)=2.41, \mathrm{p}=0.021)$ subtests, which are categorized as the negative symptoms. In addition, significant improvements were also observed in the "hostility" $(1.11 \rightarrow 1.0, \mathrm{t}(35)=2.09, \mathrm{p}=$ $0.044)$, "bizarre behavior" $(1.92 \rightarrow 1.42, \mathrm{t}(35)=2.84, \mathrm{p}=0.007)$, "mannerisms and posturing" $(1.56 \rightarrow 1.25, \mathrm{t}(35)=2.74, \mathrm{p}=0.01)$, and "disorientation" ( 1.36 $\rightarrow 1.11, \mathrm{t}(35)=2.31, \mathrm{p}=0.027)$ subtests.

\subsection{Participants' Feedback}

Figure 3 shows the participant feedback concerning whether they concentrated

Table 3. BACS results.

\begin{tabular}{ccccc}
\hline BACS & $\begin{array}{c}\text { Baseline } \\
(\mathrm{n}=36)\end{array}$ & $\begin{array}{c}\text { After the 30 } \\
\text { sessions }(\mathrm{n}=36)\end{array}$ & Change in scores & $\begin{array}{c}\text { Difference (t-test) } \\
\text { p value }\end{array}$ \\
\hline Total & -2.3 & -2.02 & -0.28 & $\mathbf{0 . 0 4 2}$ \\
Verbal memory & -1.7 & -1.53 & -0.17 & 0.38 \\
Working memory & -1.26 & -1.24 & -0.02 & 0.91 \\
Motor speed & -1.71 & -1.4 & -0.31 & 0.113 \\
Verbal fluency & -1.22 & -0.98 & -0.24 & $\mathbf{0 . 0 0 7}$ \\
Attention & -2.02 & -1.77 & -0.25 & $\mathbf{0 . 0 1 5}$ \\
Executive function & -0.51 & -0.49 & -0.02 & 0.943 \\
\hline
\end{tabular}


Table 4. BPRS results.

\begin{tabular}{|c|c|c|c|c|}
\hline BPRS & $\begin{array}{l}\text { Baseline } \\
(\mathrm{n}=36)\end{array}$ & $\begin{array}{l}\text { After the } 30 \text { sessions } \\
\qquad(\mathrm{n}=36)\end{array}$ & $\begin{array}{l}\text { Change } \\
\text { in scores }\end{array}$ & $\begin{array}{c}\text { Difference (t-test) } \\
\text { p value }\end{array}$ \\
\hline Total & 30.72 & 29.47 & 1.25 & 0.427 \\
\hline Somatic concern & 2.39 & 2.83 & -0.44 & 0.143 \\
\hline Anxiety & 2.56 & 2.5 & 0.06 & 0.851 \\
\hline Emotional withdrawal & 1.78 & 1.42 & 0.36 & 0.046 \\
\hline Conceptual disorganization & 1.78 & 1.81 & -0.03 & 0.9 \\
\hline Guilt & 2.06 & 2.08 & -0.03 & 0.913 \\
\hline Tension & 1.78 & 1.83 & -0.06 & 0.838 \\
\hline Mannerisms and posturing & 1.56 & 1.25 & 0.31 & 0.01 \\
\hline Grandiosity & 1.67 & 1.56 & 0.11 & 0.401 \\
\hline Depression & 2.08 & 2.36 & -0.28 & 0.309 \\
\hline Hostility & 1.11 & 1 & 0.11 & 0.044 \\
\hline Suspiciousness & 1.61 & 1.58 & 0.03 & 0.902 \\
\hline Bizarre behavior & 1.92 & 1.42 & 0.5 & 0.007 \\
\hline Motor retardation & 1.44 & 1.39 & 0.06 & 0.701 \\
\hline Uncooperativeness & 1.11 & 1 & 0.11 & 0.103 \\
\hline Unusual thought content & 1.44 & 1.36 & 0.08 & 0.499 \\
\hline Blunted affect & 1.64 & 1.36 & 0.28 & 0.067 \\
\hline Excitement & 1.44 & 1.61 & -0.17 & 0.461 \\
\hline Disorientation & 1.36 & 1.11 & 0.25 & 0.027 \\
\hline
\end{tabular}

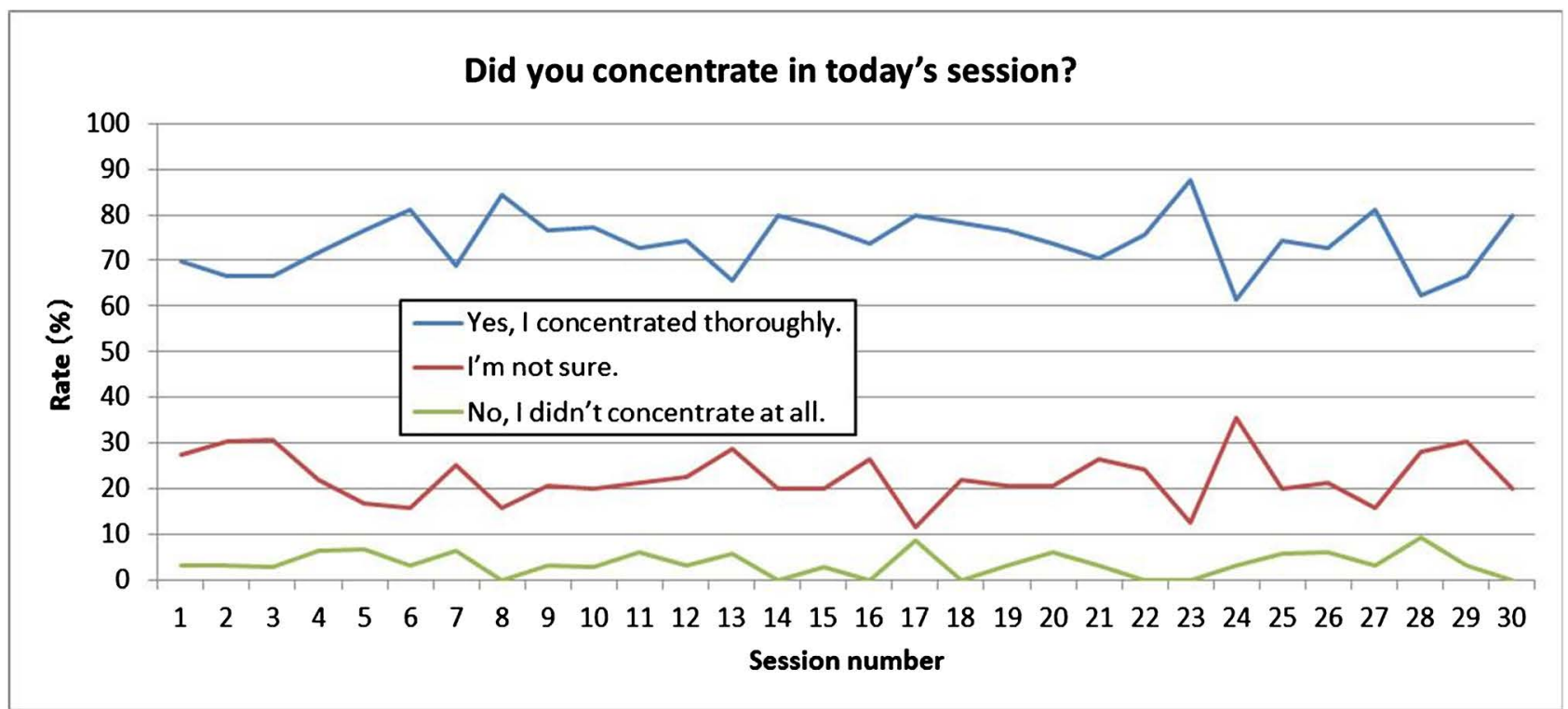

Figure 3. Results for Question 1 (Did you concentrate in today's session?). 
during the sessions (the responses to Question 1 in Figure 1). In Figure 3, because of absence, the number of participants for each session varies session by session. This also applies to Figures 4-6.

Across the 30 sessions, $74.12 \%$ of the participants on average concentrated thoroughly, while $3.5 \%$ on average did not concentrate at all. Session 24 featured the lowest rate of those who concentrated thoroughly, namely, $61.3 \%$. The cognitive theme in this session was "thinking about your thinking" (Module \#5 in Table 1).

Figure 4 shows the participant feedback concerning whether they found the sessions difficult or exhausting (the responses to Question 2 in Figure 1).

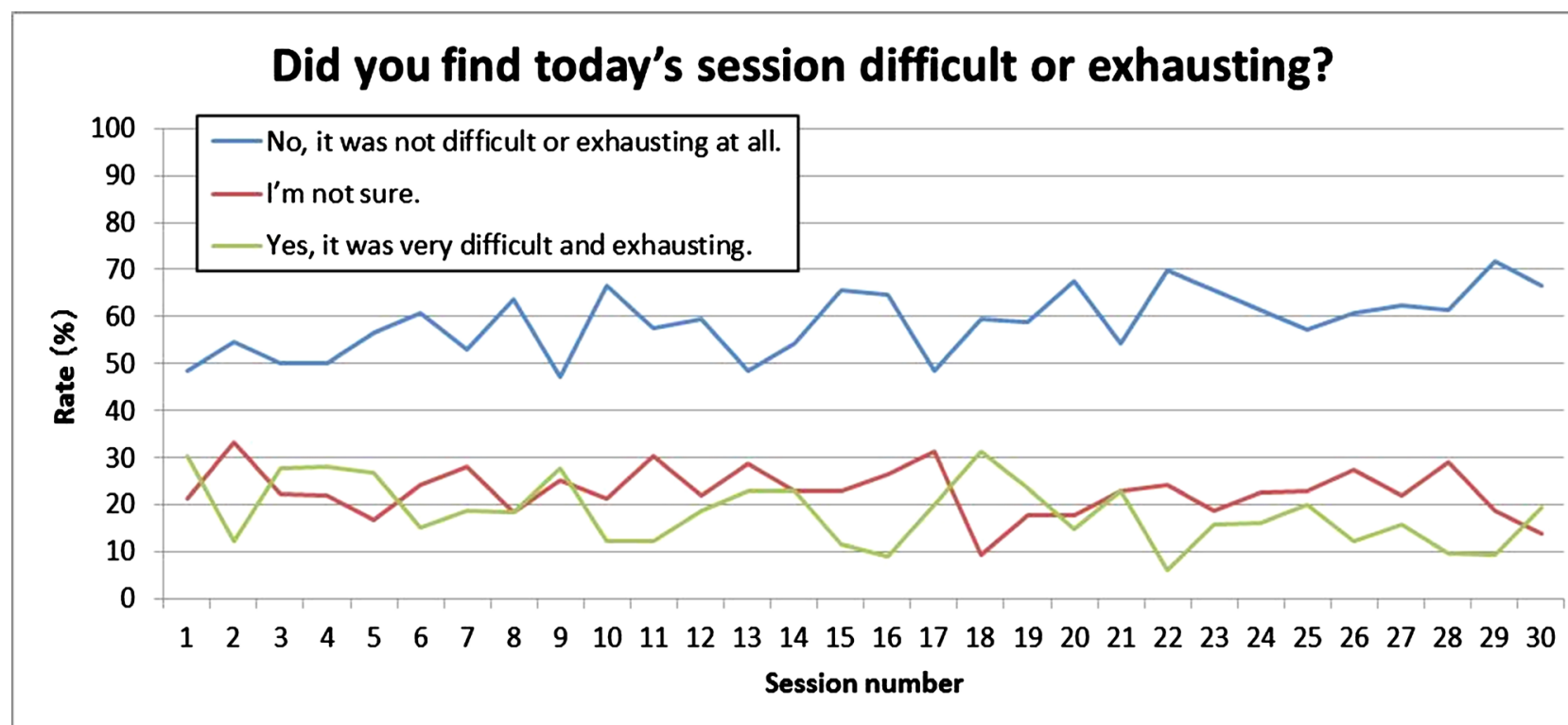

Figure 4. Results for Question 2 (Did you find today's session difficult or exhausting?).

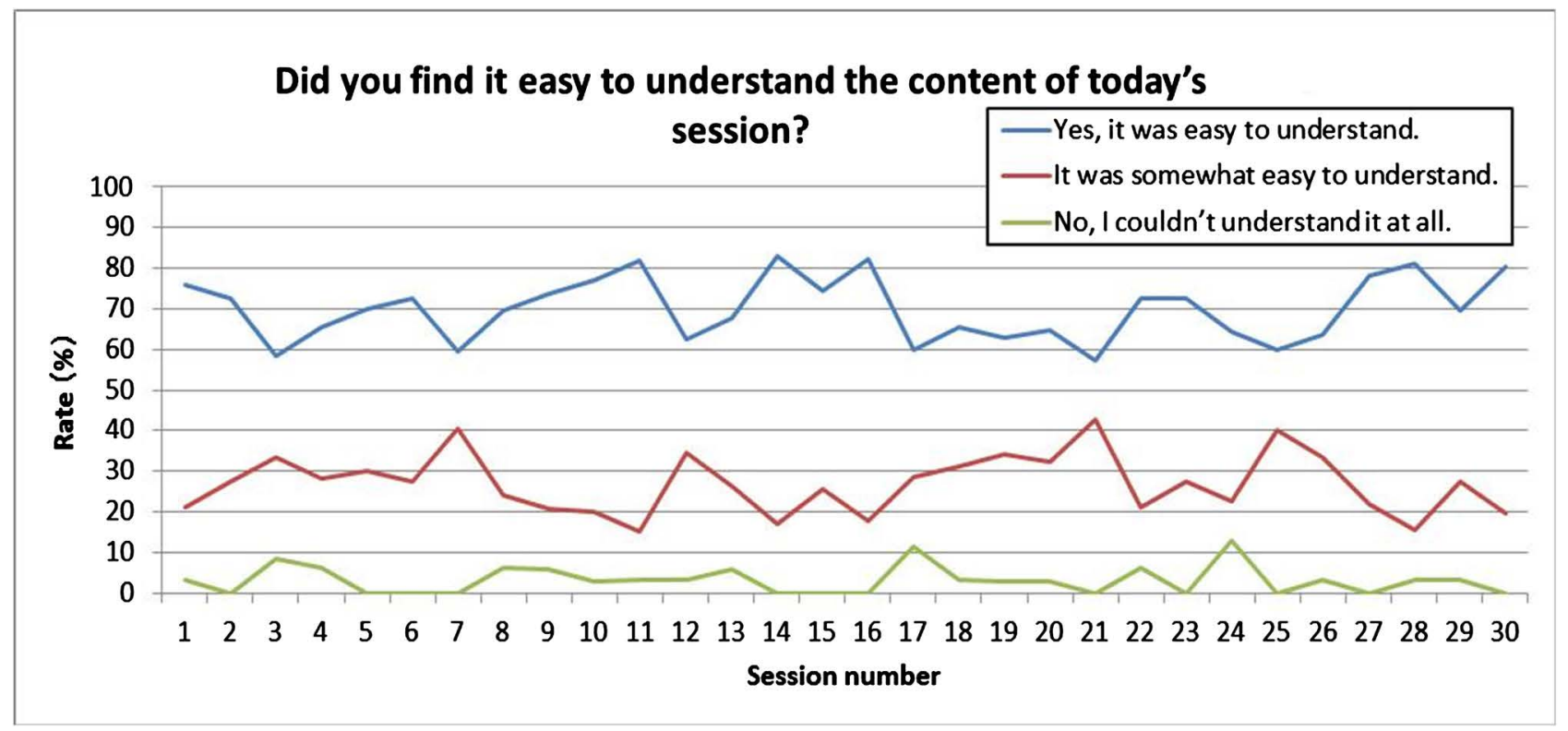

Figure 5. Results for Question 3 (Did you find it easy to understand the content of today's session?). 


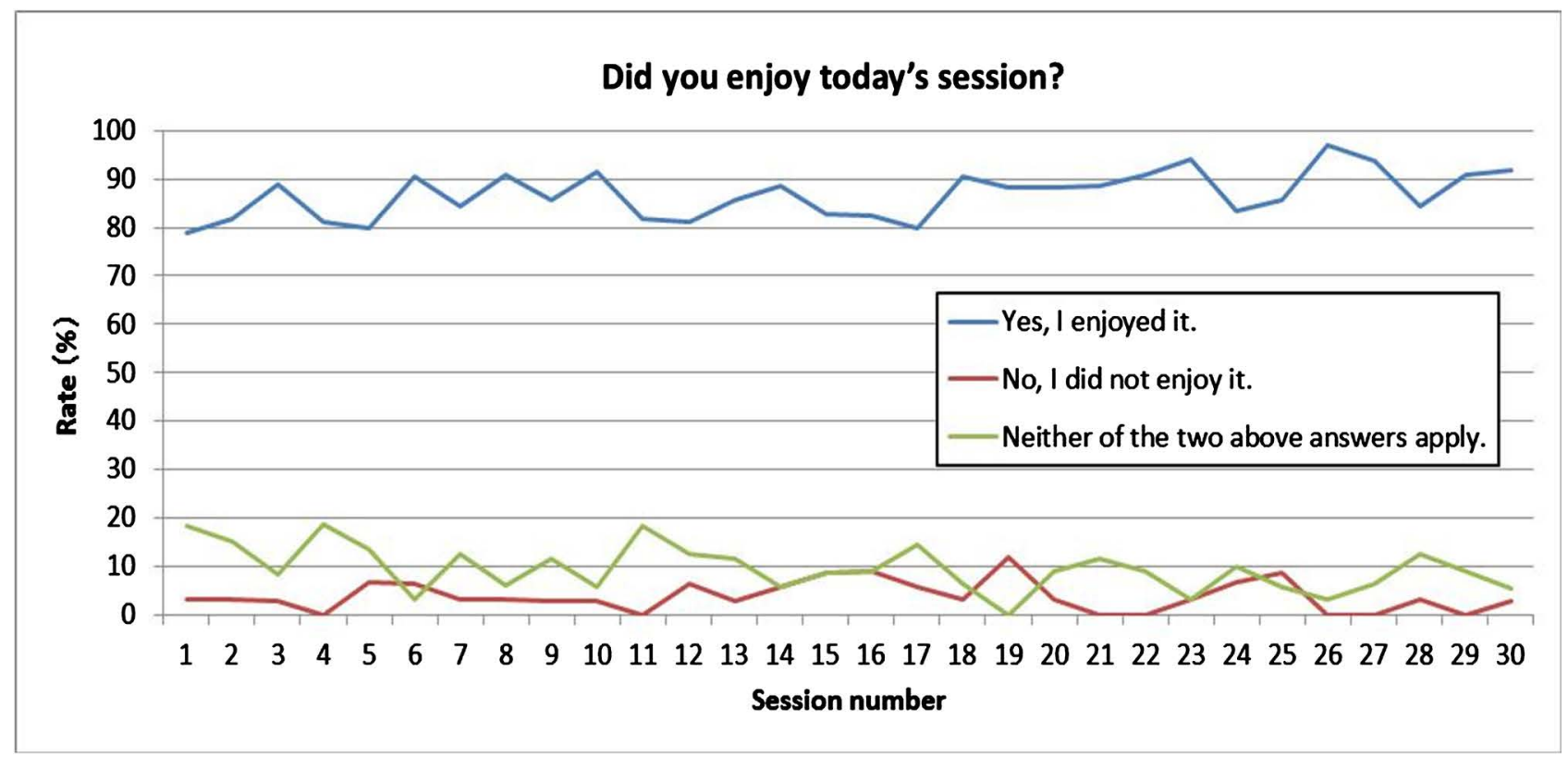

Figure 6. Results for Question 4 (Did you enjoy today’s session?).

Across the 30 sessions, $58.8 \%$ of the participants on average did not find the sessions difficult or exhausting at all, while $18.4 \%$ on average found them very difficult or exhausting. Session 9 featured the lowest rate of participants who did not find the session difficult or exhausting at all, at $47.2 \%$. The cognitive theme in this session was "problem solving" (Module \#2 in Table 1). The rate of those finding the session difficult and exhausting gradually decreased with successive sessions, suggesting that the participants grew accustomed to the program over time.

Figure 5 shows the participant feedback concerning whether they found the sessions easy to understand (the responses to Question 3 in Figure 1).

Across the 30 sessions, $70.0 \%$ of the participants on average found the sessions easy to understand, while $3.1 \%$ on average struggled to understand. Session 24 featured the lowest rate of participants who found the session easy to understand, at $12.9 \%$. The cognitive theme in this session was "thinking about your thinking" (Module \#5 in Table 1). As we saw in Figure 3, this session also featured the lowest rate of participants who concentrated well, suggesting that we should make the program content easier to understand to encourage participants to concentrate better.

Figure 6 shows the participant feedback concerning whether they enjoyed the sessions (the responses to Question 4 in Figure 1).

Across the 30 sessions, $86.8 \%$ of the participants on average enjoyed the sessions, while $9.4 \%$ on average did not. Session 19 featured the highest rate of participants who did not enjoy the session, at $11.8 \%$. The cognitive theme in this session was "summarizing the main idea" (Module \#4 in Table 1). The rate of those enjoying the session increased as they participated in more sessions, suggesting that the participants gradually started to enjoy the program. 


\section{Discussion}

The results of our study indicate that our MTCR program improved both cognitive deficits and negative symptoms. Specifically, we observed significant improvements in the cognitive performance items "verbal fluency" and "attention" and in the negative symptoms "emotional withdrawal" and "blunted affect." As regards psychiatric symptoms, the results revealed significant improvements in "mannerisms and posturing," "hostility," "bizarre behavior," and "disorientation."

In a review in Kasumi et al. [10], the effects of cognitive remediation on the seven cognitive domains are summarized as follows. Through intervention by cognitive remediation, attention/vigilance, verbal working memory, verbal learning and memory, and reasoning/problem solving were classified as "effective." The class of "likely effective" contained the speed of processing and visual learning and memory domains, and the class "possibly effective" contained the social cognition domain. It can therefore be concluded that effects were demonstrated for intervention across all seven cognitive domains. Our MTCR program significantly improved attention, and so we can say that our program's attention-improving effect was consistent with that of NEAR. However, we did not observe improvements in the other items. The lack of such improvements might stem from differences in the density of intervention between existing cognitive performance training programs (such as NEAR) and our MTCR intervention.

In a recent review, Geretsegger et al. [14] found that medium-term (more than 13 weeks) continuous intervention of music therapy had a positive impact on general mental state as measured in the Positive and Negative Symptoms Scale (PANSS), negative symptoms as measured in the SANS, and social functioning as measured in the SDSS. They found that several aspects of cognition (attention, memory, and abstract thinking) were significantly improved by medium-term music therapy as well. The effects of our 15-week-long intervention extended beyond cognitive performance and negative symptoms; we also identified significant improvements in psychiatric symptoms, namely, mannerisms and posturing, hostility, bizarre behavior, and disorientation.

We envisage four possible reasons as to why our program improved negative symptoms. 1) the intervention lasted for 15 weeks; 2) patients participated in the program as a group; 3 ) the participants frequently interacted with the therapist (the therapist also led the cognitive performance training and verbal sessions); 4) the participants' cognitive performance improved. Reason 1) is consistent with Geretsegger et al.'s study, which reported that musical therapy's psychiatric outcomes increase with continuous intervention and that these outcomes clearly emerge with medium-term intervention (13 - 26 weeks) [14]. Reason 2) is consistent with Revell et al.'s study, which reported that group-based intervention yielded significant improving effects in negative symptoms [1]. According to Revell et al., those who were willing to participate in the group program were 
strongly motivated to achieve cognitive remediation, which may explain why they were more likely to exhibit improvements. Reason 3) is consistent with Ventura et al.'s study, which reported that frequent interactions with the facilitator and therapist during cognitive performance training was a factor behind the improvements in negative symptoms. As for reason 4), we believe that an improvement of cognitive function facilitated social functioning, which in turn led to an improvement in negative symptoms. As discussed in Ventura et al. [11], improvements in cognition coupled with reductions in negative symptoms might similarly be associated with improvements in social functioning. Improvement in tracking conversations due to enhanced attention and focus might lead to improvement in social interactions by allowing patients to show a greater range of social responses. They also speculated improvement in cognition might be associated with decreasing negative symptoms such as a sociality, which might result in increased social engagement, then quantity and quality of social interactions should increase.

\subsection{Limitations}

The limitations of this study include the fact that we did not use a control group and the small size of our sample. Additionally, we did not fully explore the reasons for the improvements in verbal fluency, hostility, mannerisms and posturing, bizarre behavior, and disorientation. Accordingly, future research should use a control group for comparison, use a larger sample, and explore more thoroughly the reasons for improvements in the above items.

\subsection{Conclusion}

Our study demonstrated that MTCR program can improve both cognitive dysfunction and negative symptoms of patients with schizophrenia, which implies that it can also potentially facilitate the social participation of such patients. To further verify the effectiveness of the program, it is necessary to conduct a more reliable empirical study using a control group.

\section{Acknowledgements}

This work was supported by Grant-in-Aid for Scientific Research (C), Grant Number JP15K00157.

\section{Conflicts of Interest}

All authors declare that they have no conflicts of interest.

\section{Contributors}

Naoko Kosugi and Chiaki Oshiyama designed the study and the MTCR program, and conducted the study. Shin-ichi Niwa designed the study and MTCR program. Naoki Kodama supported statistical analyses. All authors contributed to and have approved the final manuscript. 


\section{References}

[1] Revell, E., Neill, J., Harte, M., Khan, Z. and Drake, R. (2015) A Systematic Review and Meta-Analysis of Cognitive Remediation in Early Schizophrenia. Schizophrenia Research, 168, 213-222. https://doi.org/10.1016/j.schres.2015.08.017

[2] Andrews, A., Knapp, M., McCrone, P., Parsonage, M. and Trachtenberg, M. (2012) Effective Interventions in Schizophrenia the Economic Case: A Report Prepared for the Schizophrenia Commission. Rethink Mental Illness, London.

[3] Wu, E.Q., Birnbaum, H.G., Shi, L.Z., Ball, D.E., Kessler, R.C., Moulis, M. and Aggarwal, J. (2005) The Economic Burden of Schizophrenia in the United States in 2002. Journal of Clinical Psychiatry, 66, 1122-1129. https://doi.org/10.4088/JCP.v66n0906

[4] Roick, C., Heider, D., Bebbington, P.E., Angermeyer, M.C., Azorin, J.-M., Brugha, T.S., Kilian, R., Johnson, S., Toumi, M. and Kornfeld, Å. (2007) Burden on Caregivers of People with Schizophrenia: Comparison between Germany and Britain. British Journal of Psychiatry, 190, 333-338. https://doi.org/10.1192/bjp.bp.106.025353

[5] Brekke, J.S., Hoe, M. and Green, M.F. (2009) Neurocognitive Change, Functional Change and Service Intensity during Community-Based Psychosocial Rehabilitation for Schizophrenia. Psychological Medicine, 39, 1637-1647.

https://doi.org/10.1017/S003329170900539X

[6] Green, M.F. and Nuechterlein, K.H. (1999) Should Schizophrenia Be Treated as a Neu-Rocognitive Disorder? Schizophrenia Bulletin, 25, 309-319.

https://doi.org/10.1093/oxfordjournals.schbul.a033380

[7] Ventura, J., Subotnik, K.L., Ered, A., Gretchen-Doorly, D., Hellemann, G.S., Vaskinn, A. and Nuechterlein, K.H. (2014) The Relationship of Attitudinal Beliefs to Negative Symptoms, Neurocognition, and Daily Functioning in Recent-Onset Schizophrenia. Schizophrenia Bulletin, 40, 1308-1318.

https://doi.org/10.1093/schbul/sbu002

[8] Lin, C.H., Huang, C.L., Chang, Y.C., Chen, P.W., Lin, C.Y., Tsai, G.E. and Lane, H.Y. (2013) Clinical Symptoms, Mainly Negative Symptoms, Mediate the Influence of Neurocognition and Social Cognition on Functional Outcome of Schizophrenia. Schizophrenia Bulletin, 146, 231-237. https://doi.org/10.1016/j.schres.2013.02.009

[9] Wykes, T., Huddy, V., Cellard, C., McGurk, S.R. and Czobor, P. (2011) A Meta-Analysis of Cognitive Remediation for Schizophrenia: Methodology and Effect Sizes. American Journal of Psychiatry, 168, 472-485. https://doi.org/10.1176/appi.ajp.2010.10060855

[10] Katsumi, A., Hoshino, H., Fujimoto, S. and Niwa, S. (2015) Efficacy of Cognitive Remediation in Schizophrenia: A Short Review of Its Variable Effects According to Cognitive Domain. Open Journal of Psychiatry, 5, 170-176. https://doi.org/10.4236/ojpsych.2015.52019

[11] Ventura, J., Subotnik, K.L., Gretchen-Doorly, D., Casaus, L., Boucher, M., Medalia, A., Bell, M.D., Hellemann, G.S. and Nuechterlein, K.H. (2017) Cognitive Remediation Can Improve Negative Symptoms and Social Functioning in First-Episode Schizophrenia: A Randomized Controlled Trial. Schizophrenia Research, 205, 859-866.

[12] Fusar-Poli, P., Papanastasiou, E., Stahl, D., Rocchetti, M., Carpenter, W., Shergill, S. and McGuire, P. (2015) Treatments of Negative Symptoms in Schizophrenia: Meta-Analysis of 168 Randomized Placebo-Controlled Trials. Schizophrenia Bulletin, 41, 892-899. https://doi.org/10.1093/schbul/sbu170

[13] Mössler, K., Chen, X., Heldal, T.O. and Gold, C. (2011) Music Therapy for People 
with Schizophrenia and Schizophrenia-Like Disorders (Review). Cochrane Database of Systemic Reviews, 12, CD004025. https://doi.org/10.1002/14651858.CD004025.pub3

[14] Geretsegger, M., Mössler, K.A., Bieleninik, Ł., Chen, X.-J., Heldal, T.O. and Gold, C. (2017) Music Therapy for People with Schizophrenia and Schizophrenia-Like Disorders (Review). Cochrane Database of Systemic Reviews, 5, CD004025. https://doi.org/10.1002/14651858.CD004025.pub4

[15] Cella, M., Preti, A., Edwards, C., Dow, T. and Wykes, T. (2017) Cognitive Remediation for Negative Symptoms of Schizophrenia: A Network Meta-Analysis. Clinical Psychology Review, 52, 43-51. https://doi.org/10.1016/j.cpr.2016.11.009

[16] Kosugi, N., Oshiyama, C., Kodama, N. and Niwa S. (2018) Incorporating Music Therapy into Cognitive Remediation to Improve Both Cognitive Dysfunction and Negative Symptoms in Schizophrenia. Schizophrenia Research. https://doi.org/10.1016/j.schres.2018.08.012

[17] American Psychiatric Association (1994) Diagnostic and Statistical Manual of Mental Disorders. 4th Edition, American Psychiatric Publishing, Washington DC.

[18] Keefe, R., Goldberg, T., Harvey, P., Gold, J., Poe, M., and Coughenour, L. (2004) The Brief Assessment of Cognition in Schizophrenia: Reliability, Sensitivity, and Comparison with a Standard Neurocognitive Battery. Schizophrenia Research, 68, 283-297. https://doi.org/10.1016/j.schres.2003.09.011

[19] Medalia, A. and Freilich, B. (2008) The Neuropsychological Educational Approach to Cognitive Remediation (NEAR) Model: Practice Principles and Outcome Studies. American Journal of Psychiatric Rehabilitation, 11, 23-143. https://doi.org/10.1080/15487760801963660

[20] Medalia, A., Revheim, N. and Herlands, T. (2009) Cognitive Remediation for Psychologi cal Disorders. Oxford University Press, New York. https://doi.org/10.1093/med:psych/9780195383713.001.0001 